\title{
Use of the Coulter Counter to Measure Osmotic Effects on the Swelling of Mould Spores During Germination
}

\author{
By MARY BARNES AND M. S. PARKER \\ Department of Pharmacy, University of Strathclyde, Glasgow, C. I
}

(Accepted for publication I6 May 1967)

\begin{abstract}
SUMMARY
The increase in size of Trichoderma (strain IMI I IOI50) spores during germination has been measured using the Coulter Counter. For sizing with this instrument, the spores were transferred from nutrient medium into dilute electrolyte solution and this resulted in an apparent delay in the onset of swelling. The length of this lag period was related to the concentration of saline electrolyte and not to the rate of swelling or the size of the spores.
\end{abstract}

\section{INTRODUCTION}

The swelling of mould spores, a recognized part of the germination process, has been the subject of several investigations reviewed by Sussman \& Halvorsen (I966). The most recent contributions include those of Marchant \& White (I966), Ekundayo, (I966), Barnes \& Parker (1966a) and the contributors to the Colston Papers ( 1966).

The microscopical measurement of individual spores, sampled from the germination medium, has proved to be the method of choice for following this period of growth. Other techniques involve measurement of changes in dry weight (Marchant \& White, 1966; Bartnicki-Garcia \& Nickerson, 1962), respiration rates (Mandels, Levinson \& Hyatt, 1956), packed cell volume (Mandels \& Darby, 1953; Yanagita, 1957) and extinction of suspensions (Terui \& Mochizuki, 1955).

The Coulter principle of size analysis (Coulter, 1956) involves the passage of a particle, suspended in an electrolyte solution, through a small orifice. At the same time an electric current is passed through the orifice and by displacing its own volume of electrolyte, the transient particle momentarily changes the resistance between the immersed electrodes. A small voltage pulse is produced, which is proportional in magnitude to the volume of the particle. The series of pulses, which are produced by the particles, suspended in a known volume of electrolyte, which pass through the orifice in a given time, are electronically amplified, scaled and counted.

The various models of the Coulter Counter and the techniques involved in their use have been described elsewhere (Barnes, Parker \& Bradley, 1966). The instrument measures individual particles and offers advantages over optical methods in the greatly increased number of particles measured and in the minimization of the errors and tedium involved in size analysis.

The use of automatic methods of size analysis for measuring the swelling of mould spores during germination was suggested by Barnes (1964). In subsequent investigation the Coulter Counter proved the instrument of choice. The use of this instrument 
to measure changes in volume or number of fungal cells has also been suggested by Mandels (1965).

The swelling of both mould and bacterial spores during germination is suppressed by antimicrobial agents (Mandels \& Darby, 1953; Hitchins, Gould \& Hurst, 1963). We have used the Coulter Counter to evaluate pharmaceutical preservatives by their effect upon spore swelling (Parker, Barnes \& Bradley, 1966).

This paper reports on the use of the Coulter Counter for measuring the swelling of mould spores and on the osmotic phenomena observed.

\section{METHODS}

Coulter Counter models A and B were used with $50 \mu$ orifices. Calibrations involved the use of two sources of monosized particles, polystyrene latex at $2 \cdot 956 \mu$ diameter (Dow Chemical Co.) and mould spores at $2.90 \mu$ diameter (Coulter Electronics Ltd., Barnes \& Parker, I966 b). The electrolyte consisted of solutions of sodium chloride $A / R$ in glass distilled water and was cleaned by filtration through 0.45 Millipore filters.

Spore suspensions of Trichoderma sp. strain IMI IIOI50 from 2I-day plate cultures were freshly prepared for each experiment and the spores were germinated in aerated $0.2 \%$ Malt Extract BP as described previously (Barnes \& Parker, 1966a). An exception to this procedure was when spores which had previously been stored in aqueous suspension at $4^{\circ}$ were used in investigating the effects of Chlorbutol (see Fig. 2). At intervals samples of the spores suspended in the nutrient medium were removed and 50 spores measured optically at magnification $\times 1000$ using a microscope with projection head. At hourly intervals a sample of the same germinating spores was removed and diluted approximately $\mathrm{I} / \mathrm{I} 00$ with the filtered electrolyte and the spores size-analyzed with the Coulter Counter. Thus the swelling of the same bulk sample of spores was determined simultaneously by the two methods, the spores being suspended in the nutrient medium for optical measurement and in saline solution for the Coulter analysis.

The experiments were repeated, alternating the Coulter and microscopical sizings. Duplicate experiments are shown in Fig. I. In Fig. I A the open and closed symbols represent duplicate results for $2 \mathrm{I}$-day spores in $\mathrm{I} \cdot 75 \% \mathrm{NaCl}$. Figure $\mathrm{I} B$ represents results from $2 \mathrm{I}$-day spores (closed symbols) and 28-day spores (open symbols) in I. $5 \% \mathrm{NaCl}$. The rate of swelling of the older spores was slower, a phenomenon which has previously been described (Barnes, 1964).

Chlorbutol, (2,2,2-trichloro-I,I-dimethyl-ethanol: Evans Medical Supplies Ltd., Liverpool), a preservative widely used in pharmaceutical preparations, was used to illustrate the performance of the Coulter Counter in assessing antifungal activity. Ten ml. each of double strength nutrient medium and preservative solutions of twice the required concentrations were mixed, and inoculated with $0.1 \mathrm{ml}$. of aqueous spore suspension which had been stored at $4^{\circ}$. Distilled water replaced the preservative solution in the control experiment. At intervals shown in Fig. 2 samples of the spores from the control and from each of the preservative systems were diluted with $0.9 \%$ $\mathrm{NaCl}$ electrolyte and sized on a model B Coulter Counter. 


\section{RESULTS}

The Coulter Counter Model A results are in the form of a cumulative size distribution of the large number of spores counted and sized. A convenient measurement of spore size changes during germination is the change in the size corresponding to the half-count, i.e. the numerical average size. The model B instrument automatically plots a histogram of the spore size distribution, and the change in size value correspond-

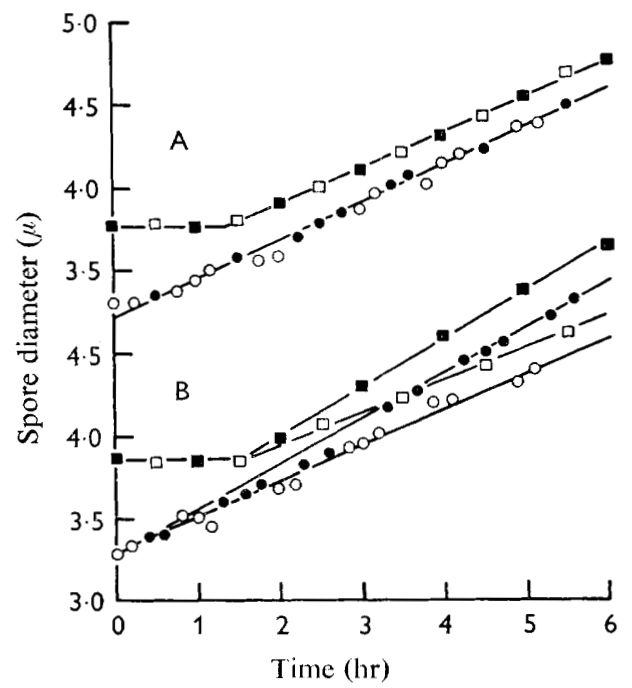

Fig. I. Spore swelling measured microscopically and by the Coulter Counter. a- $\square$ Coulter Counter results. Size units are equivalent sphere diameters corresponding to the half count. - - Optical measurements. Size units are average values of 50 spores. Open and closed symbols, duplicate experiments. Coulter Counter electrolytes: A, $1.75 \%(\mathrm{w} / \mathrm{v}) \mathrm{NaCl}$. $\mathrm{B}, \mathbf{I} \cdot 5 \%(\mathrm{w} / \mathrm{v}) \mathrm{NaCl}$.

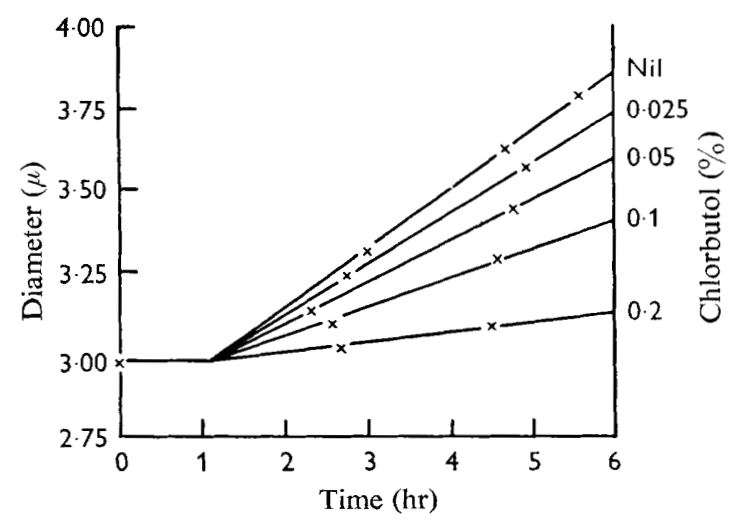

Fig. 2

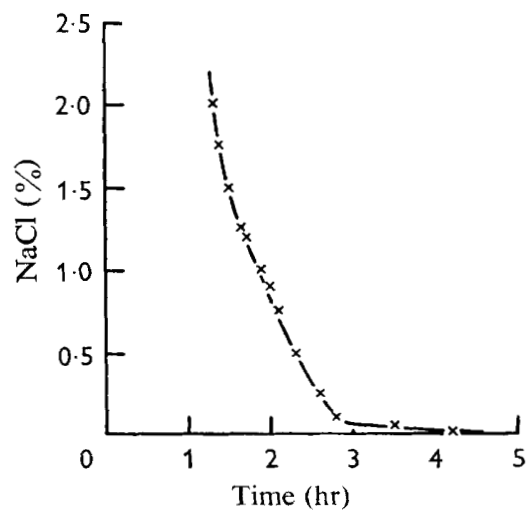

Fig. 3

Fig. 2. The effect of chlorbutol on swelling as measured by the Coulter Counter.

Fig. 3. Effect of $\mathrm{NaCl}$ concentration on time of onset of apparent swelling as measured by the Coulter Counter. 
ing to the peak of the distribution has previously been used to follow spore swelling (Parker et al. 1966) and is used in Fig. 2.

Since the size distribution of Trichoderma sp. spores is skewed (Barnes \& Parker, 1967) the peak size and the half-count size are not identical, and they differ from the arithmetic average size obtained from microscopical measurement. Comparison of the results obtained microscopically and by the Model A are shown in Fig. I. The effect of using the different criteria of spore size is shown in the separate but parallel curves.

When spores sampled in Malt Extract were measured optically there was a linear increase with time in average diameter from the beginning of the experiment (Fig. I A). The same spores, suspended in $\mathrm{I} \cdot 75 \%(\mathrm{w} / \mathrm{v}) \mathrm{NaCl}$ and sized on the Coulter Counter showed a parallel swelling, but this did not commence until I $\cdot 37 \mathrm{hr}$. Figure I B shows that when $\mathrm{I} \cdot 5 \%(\mathrm{w} / \mathrm{v}) \mathrm{NaCl}$ was used as the electrolyte this value was $\mathrm{I} \cdot 5 \mathrm{hr}$.

These experiments were repeated using a range of saline concentrations which was applicable to the instrument, i.e. from $2 \cdot 0 \%(\mathrm{w} / \mathrm{v})$ to $0.025 \%(\mathrm{w} / \mathrm{v}) \mathrm{NaCl}$. The times at which the spore swelling could be first detected were obtained and Fig. 3 shows these values plotted against the electrolyte concentration.

In order to obtain a size distribution with the Coulter Counter, about $5 \times 10^{5}$ spores were measured (cf. 50 spores per sample for optical measurements). The effect of measuring a far greater number of spores with the Coulter Counter is shown (Fig. I) by the greatly reduced scatter of the experimental determinations. Results from this instrument allowed a rate of swelling to be determined which was not ambiguous, whereas the scatter of results associated with microscopical data must be interpreted by 'goodness-of-fit' techniques. Only two or three size analyses with the Coulter Counter are necessary to determine the rate of spore swelling illustrated in Fig. 2.

\section{DISCUSSION}

Ekundayo \& Carlile (1964) found that a high osmotic pressure produced by the addition of approximately $19 \%(\mathrm{w} / \mathrm{v})$ of sucrose in the germination medium did not affect the rate of swelling of the spores of Rhizopus arrhizus. The transfer of the spores of Trichoderma sp. into electrolyte solution for Coulter Counter sizing is essentially a transfer from the nutrient medium into a medium exhibiting lower osmotic pressure. This had no effect on the rate of swelling but altered the time at which swelling is first detected by the Coulter Counter.

Since the swelling of the same bulk sample of spores was measured simultaneously by the two methods, the two curves, for example, in Fig. I A, may be superimposed. This shows that the apparent delay in the onset of swelling when the spores were transferred to electrolyte solution, was caused by an immediate increase in the size of the spores due to the uptake of water. Germination swelling was only detected with the Coulter Counter after a period of swelling in the Malt Extract when, presumably, the osmotic pressure of the spore contents had reached a value isotonic with the concentration of saline electrolyte used. For this reason Fig. 3 may be a plot of the fall in isotonicity of the germinating spores with sodium chloride solutions.

Different rates of spore swelling were involved in the duplicate experiments comprising Fig. I B, but the change in size of the spores due to immersion in electrolyte solution, and also the time at which spore swelling was detected by the Coulter Counter, are constant. This is also illustrated in Fig. 2 where the rate of swelling varies in the presence of different concentrations of chlorbutol. 
This phenomenon is explainable if the fall in isotonicity of the germinating spores is related only to the time of germination and not to the size of the spores or the rate of increase in size. It is remarkable that this relationship should hold, even when swelling is almost prevented by antifungal action and explanation is difficult.

These observations are in agreement with the work we have previously published (Barnes \& Parker, I966a), which showed that swelling during approximately the first hour of germination of freshly suspended Trichoderma sp. spores in malt extract was due to inanimate uptake of water. If spores are used which have previously been stored in water, this portion of the spore swelling should have already taken place. When the swelling of such spores was measured in $0.9 \%(\mathrm{w} / \mathrm{v}) \mathrm{NaCl}$ electrolyte, the two hours delay (Fig. 3) before the apparent onset of swelling should be reduced. Figure 2 shows that this was reduced by $56 \mathrm{~min}$.

The type of swelling curve found in this work has not been reported previously, and the osmotic phenomenon was not apparent when the swelling of Bacillus subtilis spores was measured using a similar technique (Parker et al. 1966; Parker \& Barnes, 1967). The swelling of other mould spores as measured by the Coulter Counter is being investigated since these instruments are useful for the accurate measurement of the increase in size of spores during germination.

The authors thank the Pharmaceutical Society of Great Britain and the Science Research Council for grants held by M.B. during this work.

\section{REFERENCES}

BARNES, M. (1964). The antifungal activity of Chlorocresol against germinating spores of Trichoderma viride. F.C.T. Thesis, Liverpool.

Barnes, M. \& Parker, M.S. (1966a). The increase in size of mould spores during germination. Trans. Br. mycol. Soc. 49, 487.

Barnes, M. \& Parker, M. S. (I966b). Particles for Coulter Counter calibration. Mfg. Chem. $37,57$.

Barnes, M. \& Parker, M. S. (1967). Automatic sizing of mould spores. Trans. Br. mycol. Soc. (in the press).

Barnes, M., Parker, M. S. \& Bradley, T. J. (1966). Particle size analysis and the Coulter Counter. Mfg. Chem. 37, 47 .

Bartnicki-Garcia, S. \& Nickerson, W. J. (1962). Nutrition, growth and morphogenesis of Mucor rouxii. J. Bact. $\mathbf{8 4}, 84 \mathrm{I}$.

Colston Papers (1966). No. 18 The Fungus Spore. Ed. by M. F. Madelin, London: Butterworths.

Coulter, W. H. (1956). High-speed automatic blood-cell counter and cell-size analyzer. Proc. natn. Electron. Conf. 12, I034; also U.S. Patent No. 2656508 and U.K. Patent no. 722418.

EkUNDAYo, J. A. (1966). Further studies on germination of sporangiospores of Rhizopus arrhizus. J. gen. Microbiol. 42, 283.

Ek undayo, J. A. \& CARLile, M. J. (1964). The germination of sporangiospores of Rhizopus arrhizus; spore sweiling and germ tube emergence. J. gen. Microbiol. 35, $26 \mathbf{I}$.

Hitchins, A. D., Gould, G. W. \& Hurst, A. (1963). The swelling of bacterial spores during germination and outgrowth. J. gen. Microbiol. 30, 445 .

MANDels, G.R.(1965). In The Fungi. Ed. by Ainsworth \& Sussman., Vol. I, p. 599. London: Academic Press.

Mandels, G. R. \& Darby, R. T. (1953). A rapid cell volume assay for fungitoxicity using fungus spores. J. Bact. 65, 16 .

Mandels, G. R., Levinson, H. S. \& Hyatt, M. T. (1956). Analysis of respiration during germination and enlargement of spores of Bacillus megaterium and of the fungus Myrothecium verrucaria. J. gen. Physiol. 39, 301 .

Marchant, R. \& White, M. F. (I966). Spore swelling and germination in Fusarium culmorum. J. gen. Microbiol. 42, 237. 
PARKer, M.S. \& BARnes, M. (1967). The use of the Coulter Counter to measure the swelling of bacterial spores during germination and outgrowth. J. appl. Bact. (in the press).

Parker, M. S., Barnes, M. \& Bradley, T. J. (I966). The use of the Coulter Counter to detect the inactivation of preservatives by a non-ionic surface-active agent. J. Pharm. Pharmac. 18, Suppl., IO3s.

Sussman, A. S. \& Halvorson, H. O. (I966). Spores, their Dormancy and Germination. New York and London: Harper and Row.

Terui, G. \& Mochizuki, T. (I955). Studies on the metabolism of mould spores in relation to germination-I. Technol. Rept. Osaka. Univ. 5, 219.

YANAGITA, T. (I957). Biochemical aspects on the germination of conidiospores of Aspergillus niger. Arch. Mikrobiol. 26, 329. 